\title{
Case report - Acute Corneal Subepithelial Hydrops (ACSH) during Micropulse Transscleral Cyclophotocoagulation (MPTSC)
}

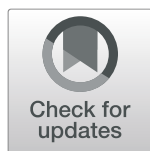

\author{
Poemen P. Chan ${ }^{1,2^{*}}$ (D), Matthew C.W. Lam ${ }^{1,2}$ and Nafees Baig ${ }^{1,3}$
}

\begin{abstract}
Background: To present an unusual intra-operative complication of micropulse transscleral cyclophotocoagulation (MPTSC).

Case presentation: A 72-year old Chinese gentleman, who had primary angle closure glaucoma and had received bilateral laser iridotomy, presented with progressive left eye blurred vision (visual acuity of 20/40 OD and 20/200 OS). Examination reviewed left eye central retinal venous occlusion. The intraocular pressure (IOP) was $19 \mathrm{mmHg}$ OS and was on maximally tolerated topical medications. Four weeks later, the left eye was complication by neovascular glaucoma; the IOP was raised to $26 \mathrm{mmHg}$ despite additional oral acetazolamide and remained elevated after panretinal photocoagulation as well as cataract extraction by phacoemulsification. MPTSC was performed 8 days after the phacoemulsification. During the procedure, a sudden protrusion was formed on the corneal surface. On-table examination with operating microscope and portable slit-lamp reviewed an intact corneal epithelium with a globular-shaped collection of fluid at the subepithelial layer - acute corneal subepithelial hydrops (ACSH). The anterior chamber was formed and the globe was intact. After approximately 10-15 minutes, the swelling spontaneously ruptured and became a corneal epithelial defect. The defect healed on the tenth day after the event with conservative management. There was no irreversible corneal damage and the patient subsequently underwent a successful second MPTSC of the left eye because of poorly controlled IOP.

(Continued on next page)
\end{abstract}

\footnotetext{
* Correspondence: poemen@gmail.com

'Department of Ophthalmology \& Visual Sciences, The Chinese University of

Hong Kong, 4/F, Hong Kong Eye Hospital, 147K Argyle Street, Kowloon,

Hong Kong SAR, People's Republic of China

${ }^{2}$ Hong Kong Eye Hospital, Kowloon, Hong Kong SAR, People's Republic of

China

Full list of author information is available at the end of the article
}

(c) The Author(s). 2020 Open Access This article is licensed under a Creative Commons Attribution 4.0 International License, which permits use, sharing, adaptation, distribution and reproduction in any medium or format, as long as you give appropriate credit to the original author(s) and the source, provide a link to the Creative Commons licence, and indicate if changes were made. The images or other third party material in this article are included in the article's Creative Commons licence, unless indicated otherwise in a credit line to the material. If material is not included in the article's Creative Commons licence and your intended use is not permitted by statutory regulation or exceeds the permitted use, you will need to obtain permission directly from the copyright holder. To view a copy of this licence, visit http://creativecommons.org/licenses/by/4.0/ The Creative Commons Public Domain Dedication waiver (http://creativecommons.org/publicdomain/zero/1.0/) applies to the data made available in this article, unless otherwise stated in a credit line to the data. 
(Continued from previous page)

Conclusion: ACSH is a possible intra-operative complication of MPTSC. We have proposed the possible mechanisms of ACSH. It is best to exercise caution when using MPTSC shortly after any incisional intraocular surgery.

Keywords: ACSH case report, Acute corneal subepithelial hydrops, MPTSC micropulse transscleral cyclophotocoagulation

\section{Background}

Micropulse transscleral cyclophotocoagulation (MPTSC; IRIDEX Laser Systems, Mountain View, CA) was approved by the Food and Drug Administration in 2015 as a treatment for glaucoma. The laser system delivers a series of short pulses of laser energy ("on" cycle) followed by pauses ("off" cycle). This cyclical delivery of laser allows energy to build up with each pulse to a photocoagulative state in the pigmented epithelium of the ciliary body, whilst the "off cycle" allows the surrounding tissue to cool down and remain below the photocoagulative threshold and, hence, preventing collateral tissue damage [1].

Compared with continuous-wave diode laser transscleral cyclophotocoagulation (DLTSC), MPTSC has demonstrated comparable efficacy with fewer side effects for treating refractory glaucoma [1-5]. With better safety profile, it was suggested that MPTSC could also be suitable for eyes with good central vision [6] and those with previous keratoplasty [7]. Reported complications of MPTSC included prolong postoperative iritis, cystoid macular oedema, loss of $\geq 2$ lines of visual acuity, and phthisis bulbi $[8,9]$. Theoretically, MPTSC could also damage the cornea since the laser probe is applied near the limbus. The eye is especially vulnerable shortly after intraocular surgery when there are wounds at the peripheral cornea. However, severe corneal complications due to MPTSC have not been reported. To our knowledge, this is the first case report of an unusual and a potentially dangerous complication of MPTS $\mathrm{C}$ - acute corneal subepithelial hydrops (ACSH).

\section{Case presentation}

The authors obtained approval of the case report by the Research Ethics Committee (Kowloon Central/Kowloon East) of the Hospital Authority, Hong Kong (Ref: KC/ KE-19-0256/ER-3). Written informed consent to publish (including individual details and images) was obtained from the patient.

A 72-year old Chinese gentleman, who had chronic obstructive airway disease (COAD) and type II respiratory failure on oxygen therapy, presented with progressive blurring of vision in his left eye. He had previously undergone bilateral peripheral laser iridotomy because of left eye advanced primary angle closure glaucoma (PACG) and right eye primary angle closure (PAC). He had opted for conservative management and had refused further intervention, such as phacoemulsification and intraocular lens (IOL) insertion, because of the poor health status and known guarded left eye visual prognosis.

At presentation, his best-corrected visual acuity was 20/40 OD and 20/200 OS. Intraocular pressure (IOP) was 13 $\mathrm{mmHg}$ OD and $19 \mathrm{mmHg}$ OS (all IOPs were measured with Goldmann applanation tonometer unless specified). His left eye was on three topical medications including topical latanoprost, brimonidine, and brinzolamide - $\beta$-blockers were contraindicated because of COAD. The cup-to-disc ratio was $0.3 \mathrm{OD}$ and 0.9 OS. Dark-room indirect gonioscopy with single-mirror Goldmann lens showed Shaffer's grade 1 angle bilaterally. On slit-lamp examination, there was no sign of inflammation, pigment dispersion or neovascularization in the anterior chamber. A left eye relative afferent pupillary defect (RAPD) was present. Dilated fundal examination (with binocular indirect ophthalmoscopy and 20D lens) of the left eye reviewed tortuous vessels with diffuse dot-blot haemorrhages; there was neither neovascularization nor macular oedema. The diagnosis of left eye central retinal venous occlusion (CRVO) was made.

After 4 weeks, IOP of the left eye rose to $26 \mathrm{mmHg}$ and neovascularization of the iris was noted. Topical atropine twice daily and oral acetazolamide $250 \mathrm{mg}$ twice daily were given. One week later, pan-retinal photocoagulation was performed on the left eye on two separate occasions (with an interval of 1 week in between). Phacoemulsification and IOL implantation were also performed under topical anaesthesia 2 months after the presentation. It was performed with bimanual technique through a $3.0 \mathrm{~mm}$ clear-corneal wound at the 12 o'clock region and two paracentesis wounds at 3 and 9 o'clock region. After injecting viscoelastic into the anterior chamber and completing a continuous curvilinear capsulorrhexis, phacoemulsification was performed with the stop-and-chop technique and cortical aspiration was performed with bimanual technique. A Tecnis ZCB00 1-Piece Acrylic IOL was then implanted into the lens capsule. Viscoelastic was then removed by aspiration and corneal wounds were sealed by stromal hydration. Mild bleeding from the iris was noted during the operation. Otherwise, it was an uneventful surgery. Topical prednisolone acetate (PRED FORTE $\left.{ }^{\star}\right) 1$ drop 6 times daily OS and topical levofloxacin (CRAVIT ${ }^{\circ} 1$ drop QID OS were given and the patient was asked to continue with all the IOP-lowering medications. Post-operative day 1 and 


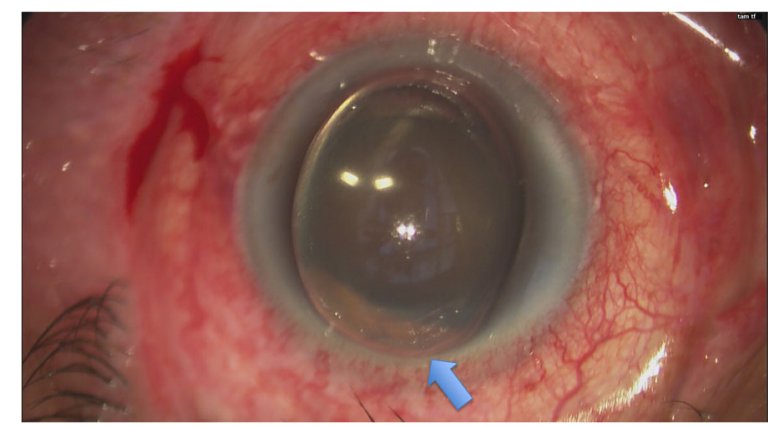

Fig. 1 (Surgeon's view) An acute globular-shaped protrusion from the corneal surface - acute corneal subepithelial hydrops (ACSH). Note the close proximity of the ACSH to the limbus at the superior aspect of the cornea (blue arrow)

day 7 showed a formed anterior chamber with mild anterior chamber cell reaction. The IOL was well-placed and stable in the posterior capsule. There was no wound leak and the cornea was clear without corneal oedema. However, left eye IOP remained at $30 \mathrm{mmHg}$ postoperatively despite three topical IOP-lowering eye drops and oral acetazolamide. After a thorough discussion with the patient on the risks and benefits of various glaucoma treatments, MPTSC was performed 8 days after the phacoemulsification and IOL implantation.

The procedure was performed in the operating theatre with retrobulbar anaesthesia (injection of a mixture of 2.5 $\mathrm{mL}$ of $0.5 \%$ Bupivacaine, $2 \mathrm{~mL}$ of $2 \%$ Lignocaine and 0.5 $\mathrm{mL}$ of $75 \mathrm{iu}$ of Hyalase). The laser setting used was 2000 $\mathrm{mW}$ of $810 \mathrm{~nm}$ infrared diode laser radiation set on micropulse mode (Iris Medical Instruments, Mountain View CA, USA). We planned to deliver the laser for $80 \mathrm{~s}$ for each superior and inferior hemisphere, sparing the 3 and 9 o'clock meridians [1]. The probe was applied with firm pressure and was moved in a continuous sliding arc motion along the superior aspect. At the 50th second, when the probe reached the 12 o'clock region, there was a spontaneous

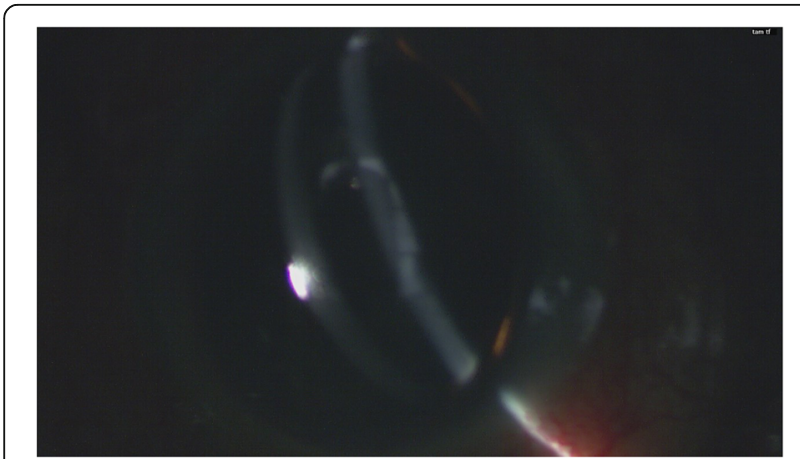

Fig. 2 Left eye examined by portable slit-lamp. Patient was in supine position. Oblique slit beam revealed fluid collection at the subepithelial layer. The anterior chamber was formed

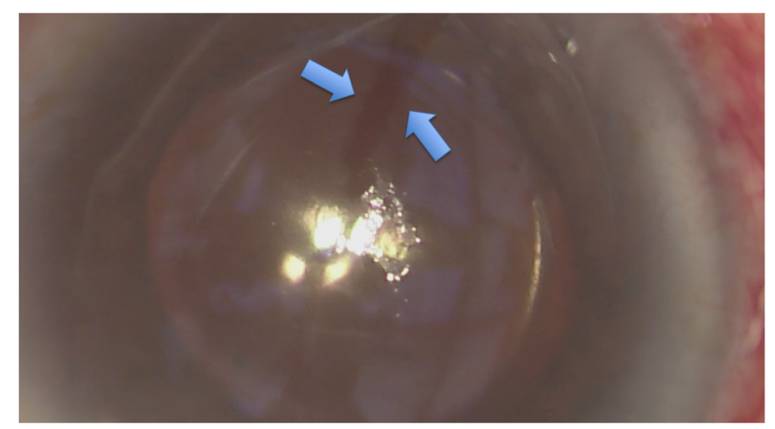

Fig. 3 Rupture of the subepithelial hydrops (corneal epithelium was indicated by the blue arrows)
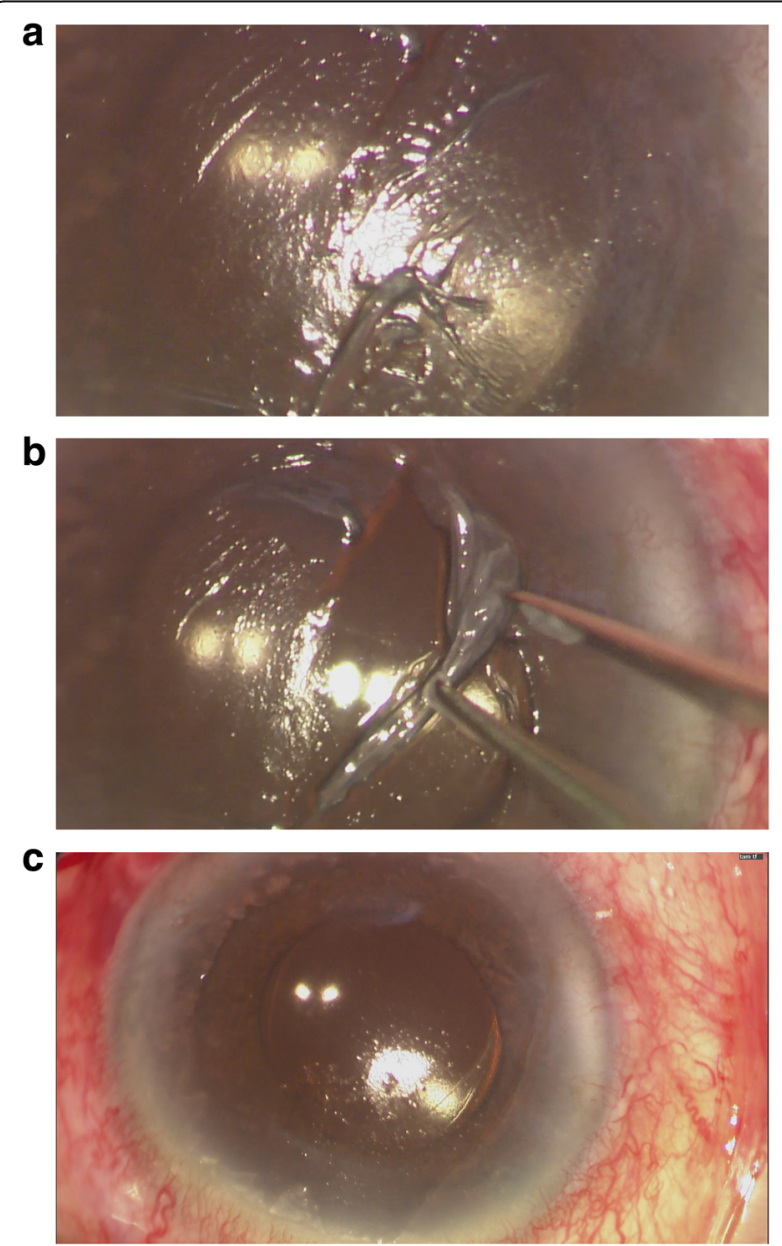

Fig. 4 a Collapse of the subepithelial hydrops after the rupture, with loose cornea epithelium. b Removal of loose epithelium with wet Merocel $^{\circledR}$ sponge and non-toothed forceps. c. Status of the cornea after the removal of loose epithelium 
formation of a globular-shaped protrusion on the corneal surface (Fig. 1). The procedure was immediately withheld and the eye was examined with an operating microscope.

As demonstrated in Fig. 1, a globular-shaped hydrops could be identified on the corneal surface. The anterior chamber was formed. Gentle digital palpation on the sclera revealed a firm pressure. Since the patient was lying in a supine posture and it was in the operating theatre setting, the eye was further examined by a portable slit-lamp. Oblique slit beam revealed that the hydrops was at the subepithelial level and the epithelium was intact (Fig. 2). The diagnosis of ACSH was made. The corneal subepithelial hydrops then spontaneously ruptured (Fig. 3) in approximately 10-15 min intra-operatively and debridement of the loose epithelium was performed (Fig. 4a-c) - hence, anterior-segment optical coherence tomography (ASOCT) was not performed to confirm the diagnosis. No leakage was identified (Seidel's test was negative), the anterior chamber was formed without signs of ruptured globe, and IOP was $23 \mathrm{mmHg}$ (measured with TONOPEN AVIA ${ }^{\circ}$, Reichert Technologies, NY, USA) before the patient left the operating theatre.

The patient was followed up on day one, day three, and day ten after the operation. All IOP-lowering medications (including oral acetazolamide $250 \mathrm{mg} \mathrm{BD}$ ) were continued. In addition, topical prednisolone acetate (PRED FORTE ${ }^{\circ}$ ) 1 drop BD OS and topical levofloxacin $\left(\right.$ CRAVIT $\left.^{\circ}\right) 1$ drop QID OS were given. Full corneal epithelialisation was achieved on day ten. The left eye IOP were $15 \mathrm{mmHg}, 6$ $\mathrm{mmHg}$, and $18 \mathrm{mmHg}$ respectively. The IOP rose to 25 $\mathrm{mmHg}$ at 1 month despite maximally tolerated medication. Further MPTSC was subsequently performed in the second month after the last MPTSC and it was uneventful. After this second MPTSC, the IOP was maintained at 15 $\mathrm{mmHg}$ with two medications (lantanoprost and brinzolamide), although visual acuity remained the same as before the events (i.e. 20/200 OS).

\section{Discussion and conclusions}

To our knowledge, this is the first publication describing an acute corneal complication of MPTSC. A rapid accumulation of fluid at the subepithelial layer led to ACSH. Given that the phacoemulsification was performed through a clear corneal wound at the 12 o'clock region 8 days prior to the MPTSC, we propose that during the MPTSC procedure, the laser probe had undesirably delivered laser energy through the main corneal wound and led to a rapid cleavage along the corneal subepithelial layer. It is possible that, because of the tight palpebral fissure, the MPTSC probe was inadvertently pushed centrally and the laser energy was misdirected towards the corneal wound (Fig. 5 - schematic diagram of the mechanism). Another possible mechanism could be related to the rapid rise in IOP during the procedure. The increased IOP - which could be due to the retrobulbar anaesthesia and/or laser energy of MPTSC could force the aqueous to areas with recently damaged Descemet's membrane (i.e. the corneal incision of the cataract surgery). Application of pressure adjacent to the wound might have stretched the wound enough to permit the influx of aqueous into the cornea and resulted in a rapid formation of the $\mathrm{ACSH}$; the temporarily and rapidly elevated IOP increases its imbibition into the corneal epithelial layer through this new channel of

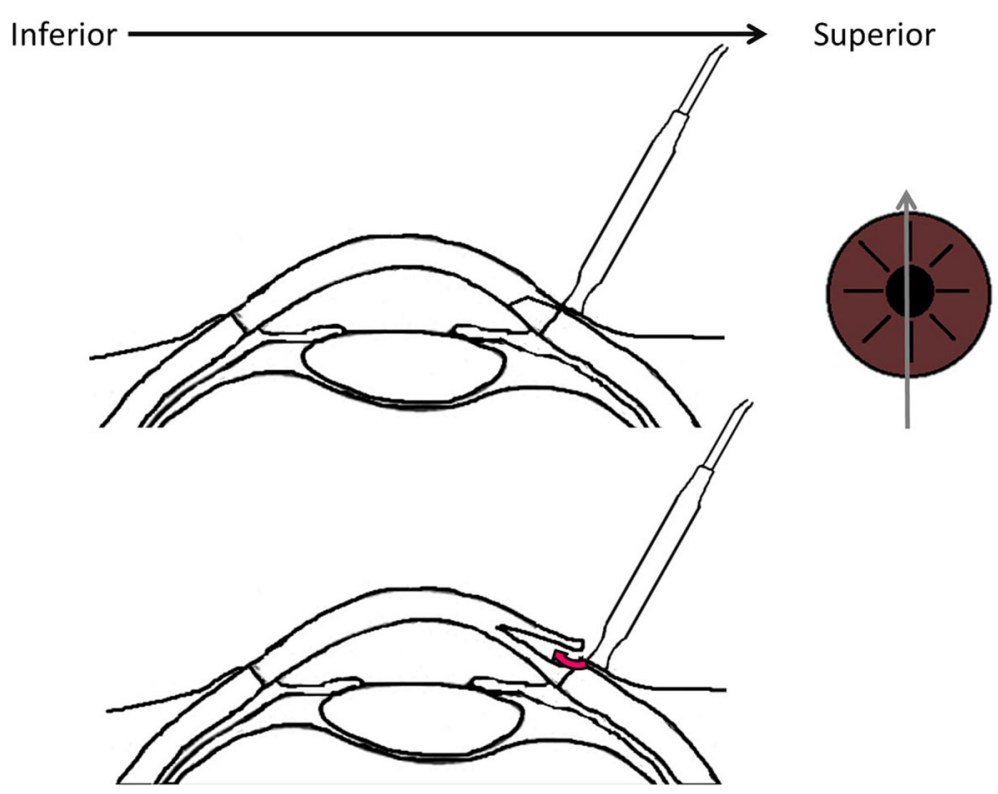

Fig. 5 Schematic diagram demonstrating how laser energy could be misdirected towards the corneal wound if the MPTSC probe is not well positioned 

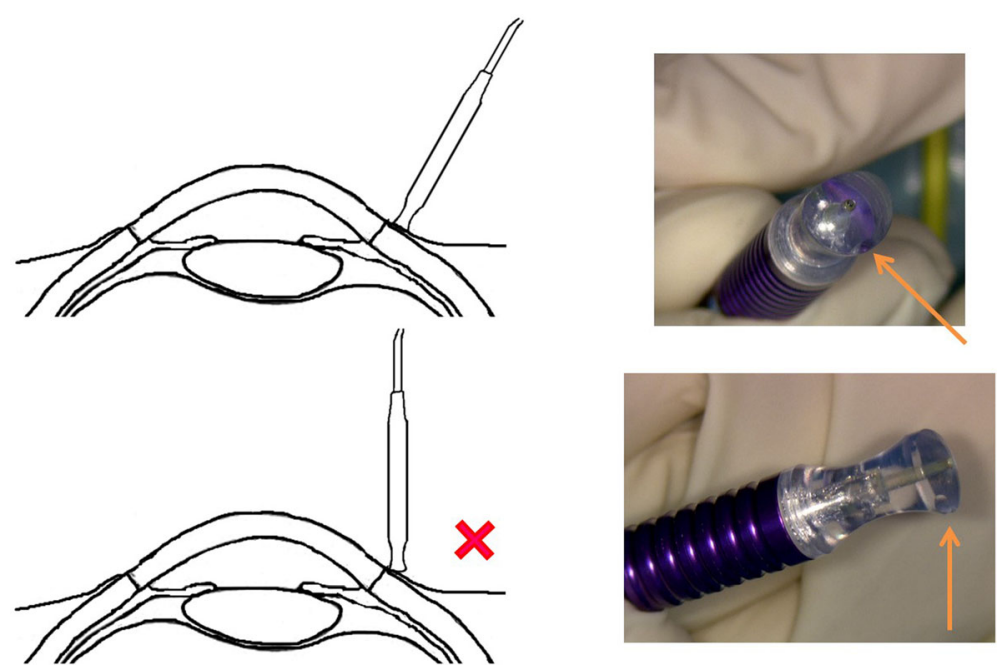

Fig. 6 Correct orientation and positioning of MPTSC probe; the notch (orange arrow) should be towards the limbus

disrupted Descemet's membrane. Either mechanism, by the same token, could have resulted in separation of the cornea at any level and produced different pathologies, such as a rapid and extensive Descemet's membrane detachment (DMD). Although the patient also has other comorbidities (e.g. COAD, on long-term oxygen, left eye CRVO, left eye neovascular glaucoma), we cannot relate any of these to the occurrence of ACSH.

The correct position and orientation of the MPTSC probe during the procedure is important (Fig. 6). Some surgeons prefer performing MPTSC without a lid speculum, because for patients with a tight palpebral fissure, the speculum might obscure the path of the sweeping motion of the probe. Squint hook could be employed to orientate an anesthetised eye, but the globe could slip whilst the probe is moving. Alternatively, two pairs of Moody fixation forceps (held by an assistant) could be used to firmly stabilise the globe for MPTSC (Fig. 7). The forceps can also serve to safeguard the 3 and 9 o'clock region from undesirable laser delivery to the long ciliary nerves and vessels.

Given that the ACSH was likely related to the new clear-corneal wound after the phacoemulsification, we suggest that MPTSC should be performed very carefully soon after any incisional intraocular surgery because of the incomplete healing of the corneal wounds shortly after operation. In a previous study, AS-OCT of the corneal incision demonstrated the presence of localised epithelial bulla, DMD and endothelial gapping 1 day after surgery [10]. Up to $37 \%$ of DMD and $20 \%$ of endothelial gapping were observed on day eight. In some patients, these could still be detectable 30 days after the operation [11]. During MPTSC, laser energy or the rapidly raised IOP could be distributed to the cornea through the wound gap, especially if the main wound is more peripherally located and if the probe is not well-positioned. In cases where early MPTSC needs to be done shortly after cataract extraction or if MPTSC is combined with
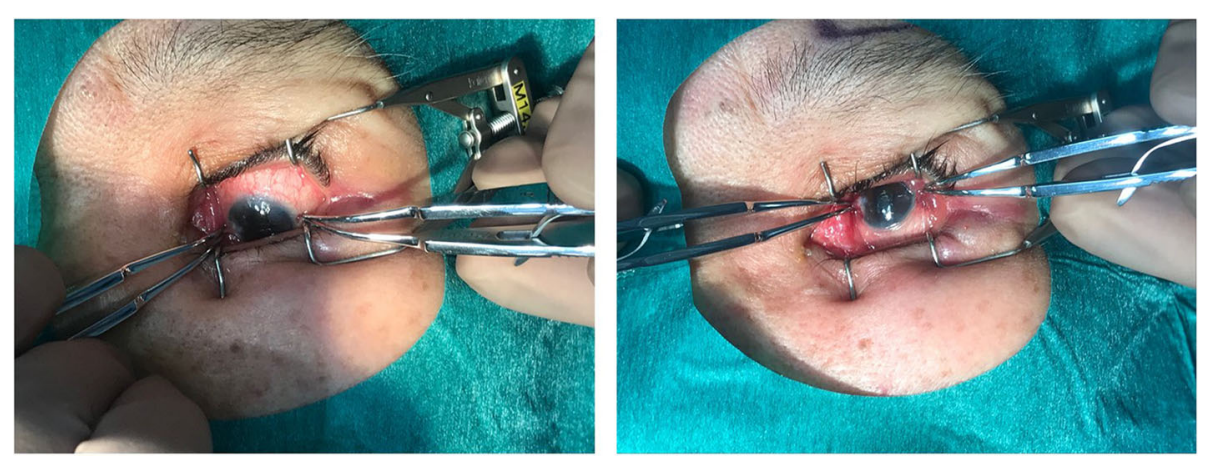

Fig. 7 Moody fixation forceps could help mobilize and fix the globe, allowing good exposure for eyes with narrow palpebral fissures 
cataract surgery, the area of the clear corneal wound should be carefully respected during MPTSC. We repeated the MPTSC uneventfully for the patient two months afterward because we believed that the cornea wound should have been completely healed by then. Pseudophakia is unlikely to be a contraindication for MPTSC, provided that the surgeon is aware of the potential complication. The current study is limited by the fact that this is the only case of ACSH in our centre; we are uncertain whether MPTSC could still lead to $\mathrm{ACSH}$ in eyes that had undergone clear-cornea incision months or years beforehand. Similarly, it is also uncertain whether ACSH could develop in corneas that had never undergone any previous surgery. Detailed structure of the ACSH was not evaluated by AS-OCT because the hydrop ruptured soon after it was formed intraoperatively.

We reported a new complication of MPTSC - acute corneal subepithelial hydrop. The case demonstrated that laser energy of MPTSC could be distributed to the cornea and lead to a potentially severe complication. It is important to apply MPTSC with correct positioning and technique, especially shortly after surgery that involved clear cornea wounds.

\section{Abbreviations}

ACSH: Acute corneal subepithelial hydrops; AS-OCT: Anterior segment optical coherence tomography; CRVO: Central retinal venous occlusion; DLTS C: Diode laser transscleral cyclophotocoagulation; DMD: Descemet's membrane detachment; IOL: Intraocular lens; IOP: Intraocular pressure; MPTS C: Micropulse transscleral cyclophotocoagulation; OD: Oculus dexter (i.e. right eye); OS: Oculus sinister (i.e. left eye); PAC: Primary angle closure; PACG: Primary angle closure glaucoma; RAPD: Relative afferent pupillary defect

\section{Acknowledgements}

No additional Acknowledgements.

\section{Authors' contributions}

PPC performed the MPTPC procedure, examined and followed-up the patient, took the clinical photos, obtaining ethics approval, wrote up and reviewed the manuscript. MCWL drew and took clinical photos for the diagrams, obtained patient's consent, applied for ethics approval and wrote up part of the manuscript. NB managed the patient and reviewed the manuscript. All authors have read and approved the manuscript.

\section{Funding}

All authors have no financial / proprietary interest in the subject matters of manuscript. No additional funding was provided for this study.

\section{Availability of data and materials}

Data sharing is not applicable to this article as no datasets were generated or analysed during the current study.

\section{Ethics approval and consent to participate}

Ethics approval was obtained from the Research Ethics Committee (Kowloon Central/Kowloon East), Hong Kong SAR. Reference no: KC/KE-19-0256/ER-3.

\section{Consent for publication}

Written informed consent to publication (including images, personal and clinical details of the participants) has been obtained from the patient.

\section{Author details}

'Department of Ophthalmology \& Visual Sciences, The Chinese University of Hong Kong, 4/F, Hong Kong Eye Hospital, 147K Argyle Street, Kowloon, Hong Kong SAR, People's Republic of China. ${ }^{2}$ Hong Kong Eye Hospital, Kowloon, Hong Kong SAR, People's Republic of China. ${ }^{3}$ Department of Ophthalmology, Hong Kong Sanatorium \& Hospital, Hong Kong, People's Republic of China.

Received: 20 May 2020 Accepted: 30 September 2020

Published online: 14 October 2020

\section{References}

1. Tan AM, Chockalingam M, Aquino MC, Lim ZI, See JL, Chew PT. Micropulse transscleral diode laser cyclophotocoagulation in the treatment of refractory glaucoma. Clin Exp Ophthalmol. 2010:38:266-72.

2. Aquino MC, Barton $\mathrm{K}$, Tan AM, et al. Micropulse versus continuous wave transscleral diode cyclophotocoagulation in refractory glaucoma: a randomized exploratory study. Clin Exp Ophthalmol. 2015;43:40-6.

3. Kuchar S, Moster MR, Reamer CB, Waisbourd M. Treatment outcomes of micropulse transscleral cyclophotocoagulation in advanced glaucoma. Lasers Med Sci. 2016;31:393-6.

4. Abdelrahman AM, El Sayed YM. Micropulse versus continuous wave transscleral cyclophotocoagulation in refractory pediatric glaucoma. J Glaucoma. 2018:27:900-5.

5. Zaarour K, Abdelmassih Y, Arej N, Cherfan G, Tomey KF, Khoueir Z. Outcomes of micropulse transscleral cyclophotocoagulation in uncontrolled glaucoma patients. J Glaucoma. 2019;28:270-5.

6. Varikuti VNV, Shah P, Rai O, et al. Outcomes of micropulse transscleral cyclophotocoagulation in eyes with good central vision. J Glaucoma. 2019; 28:901-5.

7. Subramaniam K, Price MO, Feng MT, Price FW Jr. Micropulse transscleral cyclophotocoagulation in keratoplasty eyes. Cornea. 2019;38:542-5.

8. Williams AL, Moster MR, Rahmatnejad K, et al. Clinical efficacy and safety profile of micropulse transscleral cyclophotocoagulation in refractory glaucoma. J Glaucoma. 2018:27:445-9.

9. Emanuel ME, Grover DS, Fellman RL, et al. Micropulse cyclophotocoagulation: initial results in refractory glaucoma. J Glaucoma. 2017;26:726-9.

10. Xia Y, Liu X, Luo L, et al. Early changes in clear cornea incision after phacoemulsification: an anterior segment optical coherence tomography study. Acta Ophthalmol. 2009;87:764-8.

11. Can I, Bayhan HA, Celik H, Bostanci CB. Anterior segment optical coherence tomography evaluation and comparison of main clear corneal incisions in microcoaxial and biaxial cataract surgery. J Cataract Refract Surg. 2011;37: $490-500$

\section{Publisher's Note}

Springer Nature remains neutral with regard to jurisdictional claims in published maps and institutional affiliations.
Ready to submit your research? Choose BMC and benefit from:

- fast, convenient online submission

- thorough peer review by experienced researchers in your field

- rapid publication on acceptance

- support for research data, including large and complex data types

- gold Open Access which fosters wider collaboration and increased citations

- maximum visibility for your research: over $100 \mathrm{M}$ website views per year

At $B M C$, research is always in progress.

Learn more biomedcentral.com/submission 